American J. of Engineering and Applied Sciences 4 (2): 294-300, 2011

ISSN 1941-7020

C 2011 Science Publications

\title{
Experimental Study of Load Sharing in Roller-Bearing Contact by Caustics and Photoelasticity
}

\author{
Konstandinos G. Raptis, George A. Papadopoulos, \\ Theodore N. Costopoulos and Andonios D. Tsolakis \\ Department of Mechanics, National Technical University of Athens \\ 5 Heroes of Polytechnion Av, GR-157 73, Zografou, Athens, Greece
}

\begin{abstract}
Problem statement: In this study a comprehensive methodology for calculating load sharing in Roller-bearing contact was presented based on the experimental stress-optical method of caustics and Photoelasticity. Approach: The theoretical equations describing the geometry of transmitted caustic in relation to the length of the contact zone were derived and a simple mathematical set of equations correlating the maximum diameter of transmitted caustic with the magnitude of load was given.For this contact problem, the basic theory of photoelasticity was given. Results: The techniques of caustics and photoelasticity were applied on a set of PMMA (Plexiglas) Roller-bearings and on a set of PCBA (Lexan) Roller-bearings, respectively. Conclusion: The proposed method of the caustics is a reliable alternative for measuring load distribution in Roller-bearings compared to photoelasticity technique.
\end{abstract}

Key words: Caustics measurements, photoelasticity method, roller-bearings, elastic constants, hertzian contact, contact surface, complex stress function, plane strain, poisson's ratios, light beam

\section{INTRODUCTION}

Important problems with many practical applications are the contact problems (Timoshenko and Goodier, 1970). Various contact problems of surfaces under frictionless or frictional contact have been studied by (Ciavarella and Decuzzi, 2001; Yu and Bhushan, 1996; Michailidis et al., 2001), including lubricated contacts, Durany et al. (2002) and contact between coated bodies, Schwarzer et al., (1999), with either analytical or numerical methods. For the solution of such problems, except the mechanical analysis, the experimental method of caustics (Theocaris, 1970; Kalthoff, 1993; Papadopoulos, 1993) and the photoelasticity method (Frocht, 1962) can also be mentioned. The optical method of caustics is suitable for the experimental study of singularities in stress fields created either by geometric discontinuities or by loading. In this study, the stress-optical method of caustics was used to measure the contact load of bearing rollers.

The stress distribution prevailing at a classical Hertzian contact, Johnson (1987), is used to derive a suitable complex stress function, Muskhelishvili. Then, the equations of the transmitted caustics were derived in a comprehensive final form using Laurent series expansion. The maximum diameter of the transmitted caustic is mathematically linked to the length of the bearing contact and hence the bearing load.

\section{MATERIALS AND METHODS}

A special test rig has been designed and constructed at the Laboratory of Machine Elements of the National Technical University of Athens (NTUA) for testing Roller-bearing models and the infrastructure of the Laboratory of Strength of Materials of NTUA has been used to perform the caustics measurements.

The contact problem of two cylinders: According to Hertz theory (Durany et al., 2002) when two solid spheres are pressed together with a force, a circular surface of contact of radius $\alpha$ is obtained, while, when two solid cylinders are pressed together with a force, a narrow rectangular area of contact of width $2 b$ and length 1 , is obtained. The maximum pressure occurs at the center of the contact area.

The contact problem of two cylinders can be solved by Mushkelishvili stress function $\Phi(\mathrm{z})$ (Schwarzer et al., 1999). In the case of contact between a cylinder of radius $r$ and a spherical seat of radius $R$ (Fig. 1), if the bodies are pressed together along the normal at $\mathrm{O}$ by a force $\mathrm{P}$, there will be a local deformation near the point of contact producing contact over a small surface, called surface of contact.

Corresponding Author: George A. Papadopoulos, Department of Mechanics, National Technical University of Athens,

5 Heroes of Polytechnion Av., GR-157 73, Zografou, Athens, Greece 


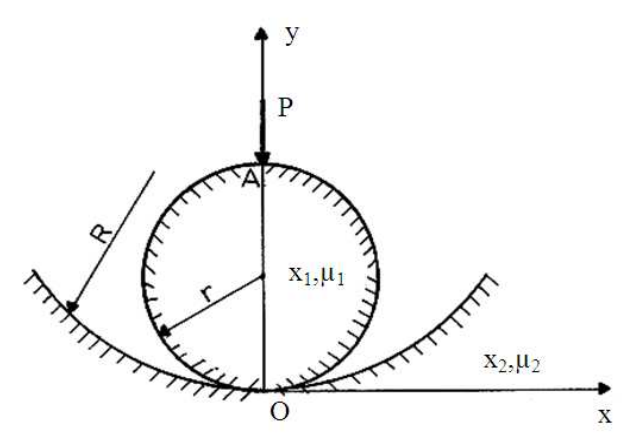

Fig. 1: Geometry of contact between a cylinder and a spherical seat

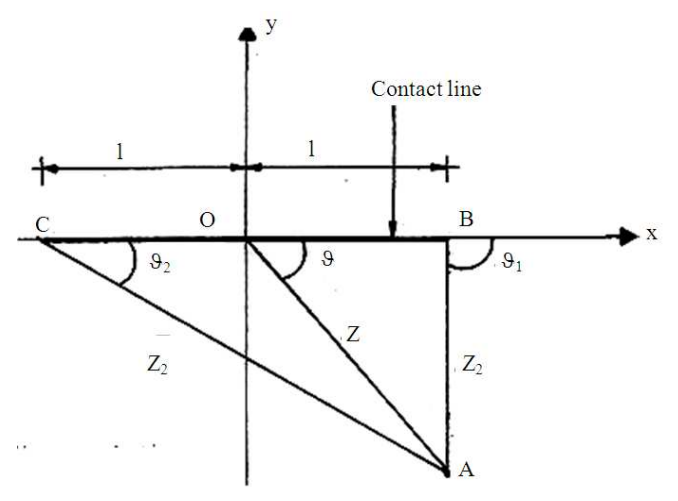

Fig. 2: Geometry of the contact line of the two bodies where $\mathrm{P}$ is a point of the initial curve of the caustic

Assuming that the radii of curvature $\mathrm{r}, \mathrm{R}$ are very big in comparison with the dimensions of contact surface, the contact surface is assumed as a line of length 21 (Fig. 2). In this case the Mushkelishvili complex stress function is:

$$
\Phi(\mathrm{z})=\frac{\sqrt{\ell^{2}-\mathrm{z}^{2}}}{2 \pi \mathrm{K}} \int_{-\ell}^{+\ell} \frac{\mathrm{f}^{\prime}(\mathrm{t}) \mathrm{dt}}{(\mathrm{t}-\mathrm{z}) \sqrt{\ell^{2}-\mathrm{t}^{2}}}
$$

With $\mathrm{z}$ being the complex variable.

From the equilibrium of forces, we obtain:

$$
\int_{-\ell}^{+\ell} \frac{\mathrm{tf}^{\prime}(\mathrm{t}) \mathrm{dt}}{\sqrt{\ell^{2}-\mathrm{t}^{2}}}=\mathrm{KP}
$$

Where:

$$
f(t)=\frac{1}{2}\left(\frac{1}{r}-\frac{1}{R}\right) t^{2}
$$

Which, was obtained from the equilibrium of displacements and:

$$
\mathrm{K}=\frac{\kappa_{1}+1}{4 \mu_{1}}+\frac{\kappa_{2}+1}{4 \mu_{2}}
$$

Where:

$\mu_{1}, \mu_{2}=$ The shear modulii of the two bodies and $\mathrm{k}_{2}, \mathrm{k}_{2}=$ The elastic constants which are given as:

For plane strain : $\kappa_{1,2}=3-4 v_{1,2}$

For plane stress : $\kappa_{1,2}=\frac{3-v_{1,2}}{1+v_{1,2}}$

where, $v_{2}, v_{2}$ are the Poisson's ratios of the material of which were made the two bodies.

For the study of this problem, the material of the two bodies was Plexiglas (PMMA) and thus the elastic constants are the same:

$\mu_{1}=\mu_{2}=\mu, \quad v_{1}=v_{2}=v, \quad \kappa_{1}=\kappa_{2}=\kappa$

For the plane stress state the $\mathrm{K}$ and $\kappa$ are given as:

$\mathrm{K}=\frac{\kappa+1}{2 \mu}$

$\kappa=\frac{3-v}{1+v}$

By integrating the stress function (1) and the Rel. (2), we obtain:

$\Phi(\mathrm{z})=-\mathrm{i} \frac{\mathrm{R}-\mathrm{r}}{2 \mathrm{KrR}}\left[\mathrm{z}-\sqrt{\mathrm{z}^{2}-\ell^{2}}\right]$

And:

$\ell^{2}=\frac{2 \mathrm{rR}}{\pi(\mathrm{R}-\mathrm{r})} \mathrm{KP}$

The force $\mathrm{P}$ is calculated by the Rel.(10), if the length 1 of contact line is known and inversely, the contact length can be calculated if the force is known. Both, force and contact length can be calculated by the experimental method of caustics.

If the two cylinders are on the either side each other, with a contact line of length 21 , the Rels (3), (9) and (10) becomes: 
Am. J. Engg. \& Applied Sci., 4 (2): 294-300, 2011

$\mathrm{f}(\mathrm{t})=\frac{1}{2}\left(\frac{1}{\mathrm{r}}+\frac{1}{\mathrm{R}}\right) \mathrm{t}^{2}$

$\Phi(\mathrm{z})=-\mathrm{i} \frac{\mathrm{R}+\mathrm{r}}{2 \mathrm{KrR}}\left[\mathrm{z}-\sqrt{\mathrm{z}^{2}-\ell^{2}}\right]$

$\ell^{2}=\frac{2 r R}{\pi(R+r)} K P$

Application of the stress-optical method of caustics for measurements of contact load: In every contact between two elastic solids a stress singularity appears because of the high strain gradients at the contact region. The optical method of caustics is able to transform the stress singularity into an optical singularity, using the reflection laws of geometric optics (Theocaris, 1970; Kalthoff, 1993; Papadopoulos, 1993) thus providing all the information needed for the evaluation of the stress singularity. According to the theory of caustics for optical isotropic materials, the equations of the initial curve and the caustic for the transmitted light rays of the convergent light beam (indicated by subscript t) are (Papadopoulos, 1993; 2005; 2004):

$$
\left|4 C_{t}^{*} \Phi^{\prime \prime}(z)\right|=1
$$

$\mathrm{W}=\lambda_{\mathrm{m}}\left[\mathrm{z}+4 \mathrm{C}_{\mathrm{t}}^{*} \overline{\Phi^{\prime}(\mathrm{z})}\right]$

With:

$\mathrm{C}_{\mathrm{t}}^{*}=-\frac{\mathrm{z}_{0} \mathrm{tc}}{\lambda_{\mathrm{m}}}$ and $\lambda_{\mathrm{m}}=\frac{\mathrm{z}_{0}+\mathrm{z}_{\mathrm{i}}}{\mathrm{z}_{\mathrm{i}}}$

Where:

$\Phi(\mathrm{z})=$ complex the stress function,

$\mathrm{z}=$ The complex variable,

$\mathrm{z}=\mathrm{x}+\mathrm{iy}$

$\lambda_{\mathrm{m}}=$ The optical setup magnification factor,

$\mathrm{z}_{0}=$ The distance between specimen and reference plane

$\mathrm{z}_{\mathrm{i}}=$ The distance between specimen and light beam focus, $t$ is the specimen thickness

$\mathrm{c}_{\mathrm{t}}=$ The stress optical constant of the specimen material

The complex stress function for the case of the contact of two elastic bodies is given by Muskhelishvili (1977):

$\Phi(\mathrm{z})=\frac{\sqrt{\left(\ell^{2}-\mathrm{z}^{2}\right)}}{2 \mathrm{kR}}+\mathrm{i} \frac{\mathrm{z}}{2 \mathrm{kR}}$
Substituting Eq. 17 into Eq. 14 and 15 the initial curve radius equation and the caustic parametric equations are obtained:

$$
\mathrm{r}=\operatorname{Re}(\mathrm{z})=\ell \sqrt{1+\left(\frac{\mathrm{C}_{\mathrm{t}}^{* *}}{\ell}\right)^{\frac{2}{3}}}
$$

Where:

$$
C_{t}^{* *}=\frac{2 C_{t}^{*}}{k R}=\frac{2 z_{0} t c_{t}}{k \lambda_{m} R}
$$

And:

$$
\begin{aligned}
& \mathrm{X}_{\mathrm{t}}=\mathrm{r} \lambda_{\mathrm{m}}\left(\cos \theta \pm \frac{\mathrm{C}_{\mathrm{t}}^{* *} \ell^{2}}{2 \mathrm{r}^{3}} \cos 2 \theta\right) \\
& \mathrm{Y}_{\mathrm{t}}=\mathrm{r} \lambda_{\mathrm{m}}\left(\sin \theta \pm \frac{\mathrm{C}_{\mathrm{t}}^{* *} \ell^{2}}{2 \mathrm{r}^{3}} \sin 2 \theta\right)
\end{aligned}
$$

The theoretical transmitted caustic curves calculated for two different contact lengths are illustrated in Fig. 3. Solid lines correspond to $2 \ell=0.002 \mathrm{~m}$, while dotted lines correspond to $2 \ell=1.6 \mathrm{~mm}$. The inner caustics (' $\varepsilon$ '-shape) correspond to focus point lying in front of the specimen and the outer caustics ('C'-shape) correspond to a focus point lying behind the specimen. For the caustics plotted in Fig. 3 it was assumed that $r=0.001 \mathrm{~m}, C_{t}^{* *}=0.001 \mathrm{~m}$ and $\lambda_{\mathrm{m}}=1$.

In Fig. 3 it becomes obvious that the maximum diameter of the transmitted caustic is parallel to the $\mathrm{x}$ axis. Therefore by measuring the maximum diameter $D_{x}$ $=2 \mathrm{X}_{\mathrm{tmax}}$ of the caustic which is parallel to the horizontal axis, the contact length 2 lcan be calculated by solving numerically the following system of equ.:

$$
\begin{aligned}
& \mathrm{D}_{\mathrm{x}}=2 \mathrm{r} \lambda_{\mathrm{m}}\left(\cos \theta+\frac{\mathrm{g}}{2} \sin 2 \theta\right) \\
& \theta=\sin ^{-1}\left[\frac{\sqrt{\left(1+8 \mathrm{~g}^{2}\right)}-1}{4 \mathrm{~g}}\right] \\
& \mathrm{g}=\frac{\mathrm{C}_{\mathrm{t}}^{* *} \ell^{2}}{\mathrm{r}^{3}}
\end{aligned}
$$

Concentrated force at a point of a straight boundary: A vertical concentrated force $\mathrm{P}$ acts on a horizontal straight boundary of an infinitely large plate (Fig. 4). The stress function is given as (Timoshenko and Goodier, 1970): 
$\Phi=-\frac{P}{\pi} r \vartheta \sin \vartheta$

The stresses $\sigma_{\mathrm{r}}, \sigma_{\vartheta}, \sigma_{\vartheta \mathrm{r}}$ are given by the relations:

$\sigma_{\mathrm{r}}=\frac{1}{\mathrm{r}} \frac{\partial \Phi}{\partial \mathrm{r}}+\frac{1}{\mathrm{r}^{2}} \frac{\partial^{2} \Phi}{\partial \vartheta^{2}}=-\frac{2 \mathrm{P}}{\pi} \frac{\cos \vartheta}{\mathrm{r}}$

$\sigma_{\vartheta}=\frac{\partial^{2} \Phi}{\partial \mathrm{r}^{2}}=0$

$\tau_{\mathrm{r} \vartheta}=-\frac{\partial}{\partial \mathrm{r}}\left(\frac{1}{\mathrm{r}} \frac{\partial \Phi}{\partial \vartheta}\right)=0$

For a circle (or disk) of diameter d (Fig. 4), at any point of the circle, the stress $\sigma_{\mathrm{r}}$ is:

$\sigma_{\mathrm{r}}=-\frac{2 \mathrm{P}}{\pi \mathrm{d}}$

From Eq. (14-15) the initial curve and the parametric equations of caustic are:

$r_{o}=r=\left(2 C_{t}\right)^{1 / 3}$

$X_{t}=\lambda_{m}\left(2 C_{t}\right)^{\frac{1}{3}}\left[\cos \vartheta+\frac{1}{2} \cos 2 \vartheta\right]$

$\mathrm{Y}_{\mathrm{t}}=\lambda_{\mathrm{m}}\left(2 \mathrm{C}_{\mathrm{t}}\right)^{\frac{1}{3}}\left[\sin \vartheta+\frac{1}{2} \sin 2 \vartheta\right]$

With:

$C_{t}=-\frac{2 z_{0} d c_{t} P}{\lambda_{m} \pi}$

For values of $\vartheta$ between $-\pi / 2$ and $+\pi / 2$, we obtain the initial curve and the respective caustic around the point of the concentrated force P. Figure 5 presents the forms of the initial curve and the respective caustic.

The maximum longitudinal diameter of the caustic along the Oy axis (Fig. 5), Can be derived from the condition:

$\frac{\partial Y_{t}}{\partial \vartheta}=0$

Which gives?

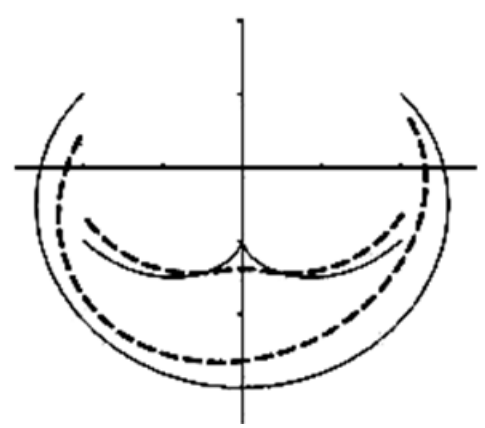

Fig. 3: Theoretical caustics for elastic contact between two bodies

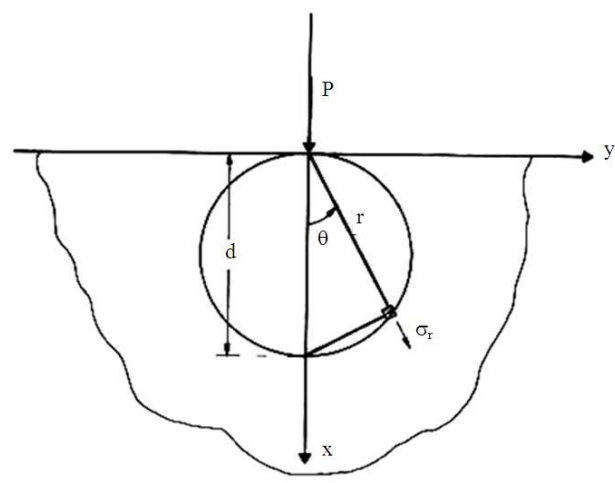

Fig. 4: Geometry of the applied force $\mathrm{P}$ at semi-infinite plate

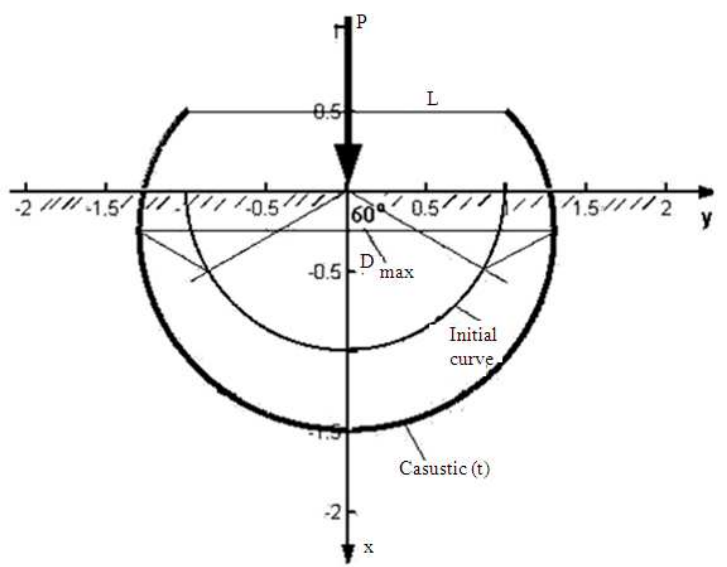

Fig. 5: Geometry of the initial curve and the respective caustic at the point of the applied force

$\vartheta^{\max }=60^{\circ}$

Relation (32), for $\vartheta=\vartheta^{\max }=60^{\circ}$, gives:

$\mathrm{D}_{\max }=2 \mathrm{Y}_{\mathrm{t}}^{\max }=\lambda_{\mathrm{m}} \mathrm{C}_{\mathrm{t}}^{\frac{1}{3}} 2^{-\frac{2}{3}} 3^{\frac{3}{2}}$ 
By substituting Rel.(33) into Rel.(36), we obtain:

$$
\mathrm{P}=\frac{2 \pi \mathrm{D}_{\max }^{3}}{81 \sqrt{3} \mathrm{z}_{0} \mathrm{~d} \lambda_{\mathrm{m}}^{2} \mathrm{c}_{\mathrm{t}}}
$$

From Rel. (37) the load P can be experimentally calculated by the diameter of the caustic which is formed at the point of its application.

The photoelastic method: According to the stressoptical law, the difference of the principal stresses is (Frocht, 1962):

$$
\sigma_{1}-\sigma_{2}=\frac{\mathrm{Nf}_{\sigma}}{\mathrm{t}}
$$

Where:

$\mathrm{N}=$ The isochromatic fringe order, $\mathrm{t}$ is the thickness of the specimens

$f_{\sigma}=$ The material fringe value or stress-optical constant

The stress-optical constant of the specimen material can be calculated by the distribution of the difference, $\left(\sigma_{1-} \sigma_{1}\right)$, of the principal stresses at the center of a disk, according to relation (Timoshenko and Goodier, 1970):

$$
\sigma_{1}-\sigma_{2}=\frac{8 \mathrm{P}}{\pi \mathrm{tD}}
$$

Then, the Rel. (38) becomes:

$$
\mathrm{P}=\frac{\mathrm{N} \pi \mathrm{f}_{\sigma} \mathrm{D}}{8}
$$

Relation (40) gives the compressive load $P$ at the center of the disk, or the stress-optical constant $f_{\sigma,}$ if the compressive load is given.

\section{RESULTS AND DISCUSSION}

In this study the load distribution in Roller bearing is studied. For this study, a simulation of Roller bearing was made (Fig. 6). Plexiglas (PMMA) specimens were used for the study by the method of caustics and Lexan (PCBA) specimens for the study by the method of photoelasticity. The thickness of the Plexiglas specimens was $0.0093 \mathrm{~m}$ and that of the Lexan specimens was $0.012 \mathrm{~m}$. The radii of inner ring were $\mathrm{R}_{\mathrm{i}, 1}=0.0055 \mathrm{~m}, \mathrm{R}_{\mathrm{i}, 2}=0.0175 \mathrm{~m}$, the radii of outer ring were $R_{0,1}=0.0305 \mathrm{~m}, R_{0,2}=0.0425 \mathrm{~m}$ and the diameter of rollers was $\mathrm{D}=0.013 \mathrm{~m}$.

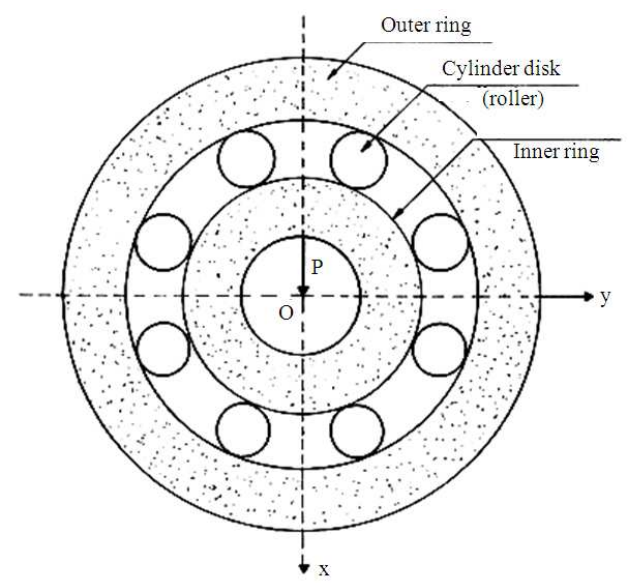

Fig. 6: Geometry of the Roller-bearing

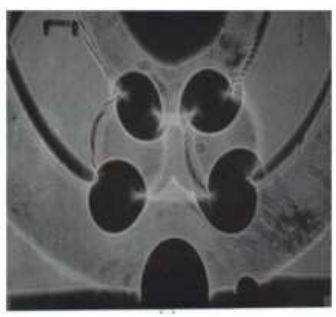

(a)

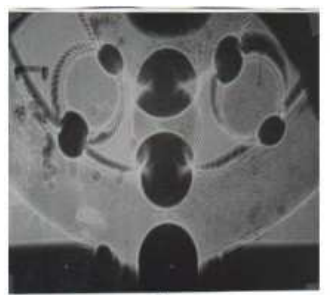

(b)

Fig. 7: Caustics at the contact points (a) for two rollers and (b) for three rollers

The specimens were loaded by a static concentrated load $\mathrm{P}$ through the inner ring of the Roller bearing (Fig. 6). Thus, the load $\mathrm{P}$ is transmitted by the inner ring to roller and then to the outer ring. The contact surfaces between rings and rollers are assumed to be points. The distribution of the stresses is given by the Hertz theory.

Figure 7 presents the caustics at the contact points between rings and rollers (a) for two rollers and (b) for three rollers configuration. The applied concentrated loads were $\mathrm{P}=72.391$ and $\mathrm{P}=94.990 \mathrm{KNm}^{-1}$ for two loaded rollers and $\mathrm{P}=68.904$ and $\mathrm{P}=98.470 \mathrm{KN} \mathrm{m}^{-1}$ for three loaded rollers. 


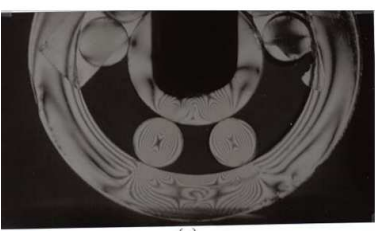

(a)

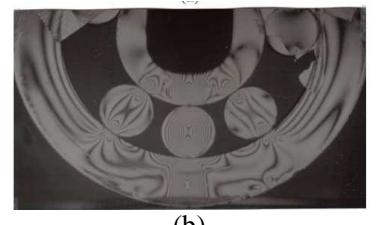

(b)

Fig. 8: Isochromatic fringe patterns at the contact points (a) for two rollers and (b) for three rollers

Table 1: Calculated loads for each roller

\begin{tabular}{|c|c|c|c|c|c|c|}
\hline $\mathrm{a} / \mathrm{a}$ & $\begin{array}{l}\mathrm{P}(\mathrm{KN} \\
\left.\mathrm{m}^{-1}\right)\end{array}$ & $\begin{array}{l}\text { Number of } \\
\text { loaded } \\
\text { rollers }\end{array}$ & $\begin{array}{l}\text { Load of } \\
\text { each } \\
\text { roller } \\
\left(\mathrm{KN} \mathrm{m}^{-1}\right)\end{array}$ & $\begin{array}{l}\text { Sum of } \\
\text { loads } \\
\left(\mathrm{KN} \mathrm{m}^{-1}\right)\end{array}$ & $\Delta \mathrm{P}(\%)$ & LSF \\
\hline \multicolumn{7}{|c|}{ By caustics } \\
\hline 1 & 72.391 & 2 & $\begin{array}{l}30.720 \\
43.020\end{array}$ & 73.74 & 1.86 & $\begin{array}{l}0.42 \\
0.59\end{array}$ \\
\hline 2 & 94.990 & 2 & $\begin{array}{l}44.010 \\
53.230\end{array}$ & 97.24 & 2.37 & $\begin{array}{l}0.46 \\
0.56\end{array}$ \\
\hline 3 & 68.904 & 3 & $\begin{array}{r}7.140 \\
57.570 \\
8.840\end{array}$ & 73.55 & 6.74 & $\begin{array}{l}0.10 \\
0.84 \\
0.13\end{array}$ \\
\hline 4 & 98.470 & 3 & $\begin{array}{l}12.020 \\
74.520 \\
16.910\end{array}$ & 103.45 & 5.10 & $\begin{array}{l}0.12 \\
0.76 \\
0.17\end{array}$ \\
\hline By & city & & & & & \\
\hline 1 & 33.250 & 2 & $\begin{array}{l}15.420 \\
15.420\end{array}$ & 30.84 & 7.81 & $\begin{array}{l}0.46 \\
0.46\end{array}$ \\
\hline 2 & 38.575 & 2 & $\begin{array}{l}18.500 \\
18.500\end{array}$ & 37.00 & 4.26 & $\begin{array}{l}0.48 \\
0.48\end{array}$ \\
\hline 3 & 45.170 & 3 & $\begin{array}{r}6.167 \\
30.830 \\
6.167\end{array}$ & 43.164 & 4.65 & $\begin{array}{l}0.14 \\
0.68 \\
0.14 \\
\end{array}$ \\
\hline
\end{tabular}

The load for each roller was calculated by the Rel.(37), with $\mathrm{z}_{0}=1.90 \mathrm{~m}, \mathrm{~d}=0.0093 \mathrm{~m}, \lambda_{\mathrm{m}}=1.923$ and $c_{t}=1.21 \times 10^{-10} \mathrm{~m}^{2} \mathrm{~N}^{-1}$. The calculated loads for each roller and the percent divergence of loads are presented in Table 1. The small divergence of the loads are caused by the lack of separators (retainers) in the model, leading to non-symmetry in the rollers. This can be seen in photographs of figures. Also, the caustics at the contact points are not symmetrical (are rotated) because of the shear loads which are created at the contact points. From photographs of Fig. 7(a) it is appeared that the angle of rotation of the caustic to be one degree. So, the shear loads were calculated about Q $=P \tan \varphi=0.536$ and $0.751 \mathrm{KN} \mathrm{m}^{-1}$.

The Fig. 8 presents the isochromatic fringe patterns at the contact points between rings and rollers and onto the rollers (a) for two rollers and (b) for three rollers configuration.
The applied concentrated loads were $\mathrm{P}=33.250$ and $\mathrm{P}$ $=38.575 \mathrm{KN} \mathrm{m}^{-1}$ for two loaded rollers and $\mathrm{P}=47.170$ $\mathrm{KN} \mathrm{m}^{-1}$ for three loaded rollers. Lexan (PCBA) specimen with a stress-optical constant $f_{\sigma}=7.2 \mathrm{KN} \mathrm{m}^{-1}$ was used. The load for each roller was calculated by the Rel.(40), with $\mathrm{D}=13 \times 10^{-3} \mathrm{~m}$ ( $\mathrm{D}$ is the diameter of the rollers). The calculated loads for each roller are presented in Table 1. The calculated Load Sharing Factor $\left(\mathrm{LSF}=\mathrm{P}_{\mathrm{i}} / \mathrm{P}\right)$ for the experimental configurations are presented in Table 1.

From the results it is concluded that both methods give accurate experimental results but a small divergence was observed which is indebted to the accurate calculations and to the fact that there was not used separators (retainers) between rollers, thus the rollers were not been in symmetric places, as it appears in photographs.

\section{CONCLUSION}

In this study the experimental stress-optical method of caustics was applied on roller-bearing specimens to determine the load sharing during multiple bearing rollers contact. The equations of the caustics were derived and used to calculate the magnitude of the applied load at each roller contact point. The obtained results of the load sharing by caustics were compared to that by photoelastic method with which good agreement was verified.

Furthermore, it was demonstrated that the proposed method has advantages over photoelasticity, because resolution of the measurements is not compromised by the small dimensions of the load bearing area and the extreme stress gradients observed in it, but instead it is reasonably accurate, highly repeatable and much faster involving a single measurement of the diameter of the projected caustic.

Apart from bearings, this technique (caustics) can be expanded in other applications such as gears, splines, chains.

\section{REFERENCES}

Ciavarella, M. and P. Decuzzi, 2001. The state of stress induced by the plane frictionless cylindrical contact II: The The general case (elastic dissimilarity). Int. J. Solids Structures, 38: 4525-4533. DOI: 10.1016/S0020-7683(00)00290-0

Durany, J., G. Garcìa and C. Vàzquez, 2002. Numerical simulation of a lubricated Hertzian contact problem under imposed load. Finite Element Anal. Design, 38: 645-658. DOI: 10.1016/S0168$874 x(01) 00097-X$ 
Frocht, M.M., 1962. Photoelasticity. Wiley, New York. http://books.google.com.pk/books?id=2svjtgAAC AAJ\&dq=Photoelasticity \&hl=en

Johnson, K.L., 1987. Contact Mechanics. Cambridge University Press, United Kingdom., ISBN: 0521347963 , pp: 452.

Kalthoff, J.F., 1993. Shadow Optical Method of Caustics. In: Handbook on Experimental Mechanics, A.S. Kobayashi (Ed.). VCH, pp: 430500. ISBN: 1560816406

Michailidis, A., V. Bakolas and N. Drivakos, 2001. Subsurface stress field of a dry line contact. Wear, 249: 546-556. DOI: $10.1016 /$ S0043$1648(01) 00542-7$

Muskhelishvili, N., 1977. Some basic Problems of the Mathematical Theory of Elasticity. 1st Edn., Springer, Moscow, ISBN: 10: 9001607012, pp: 768.

Papadopoulos, G.A., 1993. Fracture mechanics: The experimental method of Caustics and the Det.Criterion of Fracture. 1st Edn., Springer-Verlag, London, ISBN: 3540197680, pp: 285.
Papadopoulos, G.A., 2004. Experimental estimation of the load distribution in Bearings by the Method of Caustics. Exp. Mech., 44: 440-443. DOI: 10.1007/BF02428098

Papadopoulos, G.A., 2005. Experimental study of the load distribution in bearing by the method of caustics and photoelasticity, J. Strain Anal., 40: 357-365. DOI: 10.1243/030932405X15963

Schwarzer, N., F. Richter and G. Hecht, 1999. The elastic field in a coated half-space under Hertzian pressure distribution. Surface Coatings Technol., 114: $292-303 . \quad$ DOI: $10.1016 /$ S02578972(99)00057-2

Theocaris, P.S., 1970. Local yeilding around a crack tip in Plexiglas. J. Appl. Mech., 92: 409-415. DOI: 10.1115/1.3408521

Timoshenko, S.P. and J.N. Goodier, 1970. Theory of Elasticity. 3rd Edn., McGraw-Hill, ISBN: 10: 0070647208, pp: 608.

Yu, M.M.-H. and B. Bhushan, 1996. Contact analysis of three-dimensional rough surfaces under frictionless and frictional contact. Wear, $200: 265$ 280. DOI: 10.1016/S0043-1648(96)07313-9 